\title{
The Impacts of Oilfield-Related Booms and the Overall Safeties Implications in Houston Harris County, Texas and Surrounding Areas!
}

\author{
Park E. Atatah1, Catherine W. Kisavi-Atatah' \\ ${ }^{1}$ "Social Behavioral Sciences" Faculty, College of Security and Criminal Justice, University of Phoenix, Phoenix, \\ AZ, USA \\ ${ }^{2}$ Department of State Health Service, Houston, TX, USA \\ Email: peatatah12345@email.phoenix.edu,peatatah@yahoo.com, \\ catherine.atatah@dshs.state.tx.us, ckisavi@yahoo.com
}

Received 19 October 2015; accepted 14 December 2015; published 18 December 2015

Copyright (C) 2015 by authors and Scientific Research Publishing Inc.

This work is licensed under the Creative Commons Attribution International License (CC BY).

http://creativecommons.org/licenses/by/4.0/

(c) (i) Open Access

\section{Abstract}

This study investigates the impacts of oil/gas hydraulic fracking in Houston Harris County, Texas and surrounding areas. Recently, the increase in preventable roads accidents had been a concern to many Houstonians and surrounding areas residents. Further, the deplorable condition of the public roads was yet another concern primarily blamed on the implications of oil and gas hydraulic fracking in Houston Harris County, Texas and surrounding areas. The study found a statistical significant difference in Houston population increase between 2010 and 2014 as hydraulic fracking expands. We also found a symmetric statistical significant increase in fatal roads' accidents in less than 5 years, along with deplorable infrastructures. Additionally, we found a continued symmetric collective price drops in oil and gas; yet, the price of Houston, Texas median house increased astronomically to unaffordable levels for native Houstonians. The outlined findings of this study should hopefully pinpoint some of the public policy implication issues created by excessive hydraulic fracking in Houston Harris County, Texas and surrounding areas. Finally, the pinpointed recommendations should be useful in refocusing public policy decision makers in addressing some of the identified pressing public policy implications in Houston Harris County, Texas and surrounding areas; which could possibly bring some positive social changes eventually.

\section{Keywords}

Hydraulic Fracking, Oilfield-Related Boom, Houston Roads' Fatalities, Deplorable Infrastructures 


\section{Introduction}

There is no doubt that the roads' conditions in Houston Harris County, Texas along with the surrounding areas and counties are currently in deplorable conditions. The deteriorations associated with the "roads'state of minds" are unimaginable in all fields. First, endless statistics has shown that Houston Harris County, Texas leads the nation in fatal driving while intoxicated (DWI) accidents. Houston Harris County, Texas has also led the way in commercial vehicle accidents since 2009 till date according to Olsen (2014) [1], investigative report in Houston Chronicles. In addition, it should be noted that majority of the commercial vehicles' accidents are attributed to the overnight booms of oilfield related businesses along with natural gas associated with hydraulic fracking operations (Schneider, 2014) [2]. They called it fracking; which had changed the landscapes for Houston Harris County, Texas and surrounding areas, yet, accompanied by the newcomers to Houston Harris County, Texas and beyond. These newcomers have contributed to the dreadlocks in almost all Houston's highways such as Hwy 59, Hwy 69, Hwy 45, Hwy 290, I-45, and not to mention I-10 freeway but to merely mention a few. Efforts to catch-up with the overgrowths are compromised on a daily basis. Many argued that Hwy 59 is currently known as the (59 Square) freeway. Initial interviews concerning the new name for Hwy 59 indicated that the "Square" associated with Hwy 59 means "be ready for the unknown.” This is yet another challenge associated with "Oil Boom; but, Houston must boom; regardless” some claimed.

In addition to the above mentioned, many victims of vehicles accidents in Houston and surrounding areas have blamed the oil companies for undermining the issues associated with the conditions of the commercial vehicles. Also, they believed that the primary goals and objectives of the oil companies is profitability regardless of its outcomes. Above all, many have blamed the public organizations for not taking needed immediate interventions in addressing these unsafe issues that have plagued the state of Texas. For example, many have argued that the quality of obtaining private and commercial drivers' licenses has diminished yearly. They also argued that some licensed private and commercial drivers in the state of Texas in general and Harris County in particular, lack simple driving skills' proficiencies. Periodically, some commercial and private drivers drive on the wrong sides of the roads comfortably.

\section{Lack of Transparency}

In addition, others have been known to drive at night without lights because they just forgot to turn on their headlights. Finally, DWI is the number one roads' accidents killers in the state of Texas. These issues bring some lingering questions that have not been looked into carefully by the public organizations, private organizations, political leaders, and social scientific researchers due to possible lack of organizations' interests other than profitability. This brings another area associated with the booming of the oilfield-related companies' refusal to be transparent to the public as a whole. For this reason, as yelled by many oilfield-related companies employees is, "drill, drill, babe drill babe, for the profit," it became a slogan of success of the "hydraulic fracking effects" in Houston Harris County and surrounding areas. The solutions to these public prevailing concerns are overwhelming, but endless.

In fact, the question now becomes what could be the resolution and satisfactory scholarly social scientific research solutions that could possibly resolve the public and private impacts of fracking? This has become asystematic and asymmetric debatable question accompanied by endless solutions. On one hand, the oilfield related companies' employees have argued that fracking has improved the lives of many Houstonians in particular and Texas, in general. Contrarily, environmentalists, public safety officials, and public health personality's officials argued that the oilfield related employees have not realized the impacts of their activities enough to the public due to privacies that promote profitability. Also, they argued that keeping their activities private from the public interferes with the fundamental principles of transparency.

Transparency allows citizens' participation by gaining access to organizational operationswhich in turns promotes employees' accountability, as well as responsibility. Furthermore, transparency allows citizens of a democratic societyto control public employees by reducing corruptions, bribery, and other malfeasance (Elger, 2008; [3] Elger, 2011; [4] Schauer, 2011; [5] Theoharis, 1998 [6]). Finally, transparency allows the government to provide vital information to the public coupled with concerns about protecting citizens' privacy rights so they are not exposed to "adverse consequences, retribution or negative repercussions" from information provided by governments (Elger, 2011; [4] Michael, 1990; [7] Theoharis, 1998 [6]). For example, Texas Department of Criminal Justice-Parole Division (TDCJ-PD) organizational support and promotion of transparency will une- 
quivocally lead to improved management oversights and accountability. But, this is not the case specifically.

Transparency should also improve the relationship between oilfields production companies the citizens of Houston Harris County, Texas and surrounding areas. First, unequivocal transparency should lead to bridging the gaps between these entities by coming together with some workable plans to address the current Houston highways "state of minds." Secondly, transparency should allow the parties to be overly open in addressing the pros and the cons associated with booming and side effects (negative or positive) of booming in Houston and surrounding areas. Thirdly, coming together should allow these entities to see eye to eye for the first time in while on how to address some of the lingering problems associated with the oil drilling industries in Houston Harris County, Texas and surrounding areas. Finally, coming together of the entities should address some lingering questions concerning the outlook state of minds of the roads conditions in Houston, Texas and surrounding areas.

\section{Opened Research Questions}

As such, endless opened questions such as the below enlisted should and must be addressed by the involved entities.

\section{Questions}

1) What are the impacts of hydraulic fracking popularities in the Houston Harris County, Texas and the surrounding suburban areas?

2) What are the public health implications of hydraulic fracking in the Houston Harris County, Texas and the surrounding suburban areas?

3) What are the financial impacts of hydraulic fracking on the native citizens of Houston Harris County, Texas and the surrounding suburban areas?

4) What are the medical implications of hydraulic fracking in the Houston Harris County, Texas and the surrounding suburban areas inhabitants?

5) What are the short, long, and immediate environmental impacts of hydraulic fracking on the native citizens of the Houston Harris County, Texas and the surrounding suburban areas?

6) What is the immediate, short-term, medium-term, and long-term "state of mind" of roads and driving conditions in Houston Harris County, Texas and the surrounding suburban areas?

7) What are the roads' public safety implications associated with hydraulic fracking in the Houston Harris County, Texas and the surrounding suburban areas?

8) What ways can we resolve the immediate quagmires created by hydraulic fracking in the Houston Harris County and the surrounding suburban areas?

These are a few of the lingering opened research questions that need to be holistically addressed by quality scientific and social scientific researchers to make some senses concerning the general implications of fracking in Houston Harris County, Texas and surrounding suburban areas.

\section{Lack of Collaboration}

In fact, there are endless discrepancies between interest groups when dealing with fracking in the areas. First, oilfield related companies' personalities have repeatedly argued that there were no adverse impacts of fracking on the environment or citizens of the related environments. In addition, they added that fracking is the future that brought unimaginable financial blessings to the Houston Harris County, Texas and the surrounding suburban areas. Additionally, they summed that fracking is the future of Houston Harris County, Texas and the suburban surrounding areas thereafter. As such, citizens, politicians, representatives, natives, and the public should and must rally behind fracking in Houston Harris County, Texas and the surrounding suburban areas.

Contrary to the above, environmentalists saw fracking as the "Cousins of the financial Devils."

Environmentalists argued that the impacts and overall implications of fracking on the environment andthe people in the areas cannot and must not be understated or underrated. First, according to the environmentalists, fracking is responsible for the contamination of rural water wells due to the chemicals used in fracking that ended up in local wells undergrounds. However, the oilfield drilling companies denied this allegation. Secondly, environmentalists argued that fracking is responsible for some recently noticeable mini-earthquakes in rural 
Texas as far as Oklahoma, but the oilfield companies strongly denied this allegation. They claimed that miniearthquakes are naturally occurring regardless of their fracking activities in the areas. Further, they summed that mini-earthquakes are classified as earth's generational derivatives rather than the derivatives components of the fracking industries. The question now becomes what do you believe and how do you believe it since the local and state government have argued that fracking is a blessing to Houston Harris County, Texas as well as the surrounding rural areas.

\section{Methodology}

This study investigated the roles of hydraulic fracking in Houston Harris County, Texas and surrounding areas by using Non-Experimental Descriptive Statistics measurements design concentrating on Houston data between 2010 and 2013. Non-Experimental Descriptive study statistically examines or secondary data and makes some social scientific senses out of the outcomes of data analyses (see Creswell, 2009; [8] Frankfort-Nachmias \& Nachmias, 2000 [9]).

\subsection{Research Design}

In order to make some sense from the hydraulic fracking unequivocal controversial debates, the following statistics was measured with quantitative analyses' calculations. These measurementsshould shed some lights on the microscopic or macroscopic impacts of fracking on the environments as well as its impacts on the native citizens of Houston Harris County, Texas and the rural surrounding areas.

\subsection{Data Collection}

These available data were extracted from the City of Houston and surrounding areas database between 2010 and 2013.

1) The population of Houston Harris County, Texas in 2010, 2011, 2012, and 2013.

2) The median single family home price in 2010, 2011, 2012, and 2013.

3) The numbers of fatal vehicle accidents in Houston Harris County, Texas in 2010, 2011, 2012, and 2013.

4) The price of oil an barrel in 2010, 2011, 2012, and 2013.

5) The price of a gallon of gas in Houston Harris County, Texas in 2010, 2011, 2012, and 2013.

6) And finally, the numbers of deadly vehicle accidents in Houston Harris County, Texas in 2010, 2011, 2012, and 2013.

\subsection{Estimated Data}

The below analyzed tables and figures illustrated some lights on the impacts of fracking on the environment and the native citizens in Houston Harris County, Texas and the surrounding areas.

These analyses will stick to four years possible differences as our indicators' benchmark of measurement. The premises of the statistical significant differences multiplier (SSDM) formula is based on the assumption that it is possible to accurately estimate actual occurrences based on previous occurrences when dealing with missing data, especially if previous occurrences' statistics are historically consistent. According to Acock (2005), [10] Ader (2008), [11] Ader and Mellenbergh (2008), [12] Messner (1992), [13] Stoop et al. (2010), [14] Allison (2001), [15] Stake (2005), [16] Rubin (1976), [17] and Rubin and Little (2002), [18] researchers can use the known data values to accurately calculate the statistical values or estimates (unknown) data within the distributions by incorporating estimated formulas that accurately predict the values of the missing data based on available dataset's statistics. As previously developed by Atatah et al. (2013), [19] SSDM was used in data analyses to establish some statistical significant differences' facts in obtaining the data for 2014 individual items.

To simply understand to what extent the oilfield-related booms in Houston Harris County Texas and surrounding areas impacted living in Houston, several quantitative data factors were analyzed. These factors were the symmetric rather than ultra-gradual, systematic population growth in Houston Harris County, Texas and surrounding areas. Secondly, the growths of road accidents' deaths were reviewed. Also, the endless rises in price of oil barrel as well as the increases in daily gas' price were also analyzed. In addition, the medium home price in Houston Harris County Texas and surrounding areas were analyzed. The findings of these statistical analyses 
are shown in the tables and figures below in the measurements of central tendency, dispersion, and the use of Atatah et al.'s SSDM to obtain missing data for 2014 year. It is fair to note that, in this case, measurements of the sample distribution such as skewness and kurtosis were not needed. Furthermore, they were not overly statistically analyzed due to overwhelming equivocal similarities in-between and in within selected sample data from 2010 to 2014. The results of these analyses are as followed.

\section{Results of the Study}

\subsection{Population}

As shown, Table 1, Table 2, Figure 1 and Figure 2 indicated the population mean $(M)$ in Houston Harris County Texas to be 4412, 835, the minimum and maximum were 4,092,459 and 5204, 224 respectively. The standard deviation (SD) was 415,587 while the Standard Error of Mean (Std.EM) was 201, 956 and the cumulative data analyses showed no messing data as shown in Table 2 (see Table 1, Table 2, Figure 1 and Figure 2 as shown). These data showed that Houston Harris County population rose from 4.09 million to 5.20 million or approximately 21\% from 2010 to 2014 in population increase as shown.

Table 1. Houston Harris County population 2010 to 2014.

\begin{tabular}{|c|c|c|c|}
\hline \multicolumn{4}{|c|}{ Statistics } \\
\hline \multicolumn{4}{|c|}{ Houston Harris County Population 2010 to 2014} \\
\hline \multirow{2}{*}{\multicolumn{2}{|c|}{$\mathrm{N}$}} & Valid & 5 \\
\hline & & Missing & 0 \\
\hline & Mean & & $4,412,834.6000$ \\
\hline & Std. Error of Mean & & $201,955.80275$ \\
\hline & Median & & $4,253,963.0000$ \\
\hline & Mode & & $4,092,459.00^{\mathrm{a}}$ \\
\hline & Std. Deviation & & $451,586.90341$ \\
\hline & Variance & & 203,930,731,331.300 \\
\hline & Range & & $1,111,765.00$ \\
\hline & Minimum & & $4,092,459.00$ \\
\hline & Maximum & & $5,204,224.00$ \\
\hline & Sum & & $22,064,173.00$ \\
\hline
\end{tabular}

${ }^{\mathrm{a}}$ Multiple modes exist. The smallest value is shown.

Table 2. Frequency percent valid percent and cumulative percent analyses.

\begin{tabular}{|c|c|c|c|c|c|}
\hline \multicolumn{6}{|c|}{ Houston Harris County Population 2010 to 2014} \\
\hline & & Frequency & Percent & Valid Percent & Cumulative Percent \\
\hline \multirow{6}{*}{ Valid } & $4,092,459.00$ & 1 & 20.0 & 20.0 & 20.0 \\
\hline & $4,176,674.00$ & 1 & 20.0 & 20.0 & 40.0 \\
\hline & $4,253,963.00$ & 1 & 20.0 & 20.0 & 60.0 \\
\hline & $4,336,853.00$ & 1 & 20.0 & 20.0 & 80.0 \\
\hline & $5,204,224.00$ & 1 & 20.0 & 20.0 & 100.0 \\
\hline & Total & 5 & 100.0 & 100.0 & \\
\hline
\end{tabular}




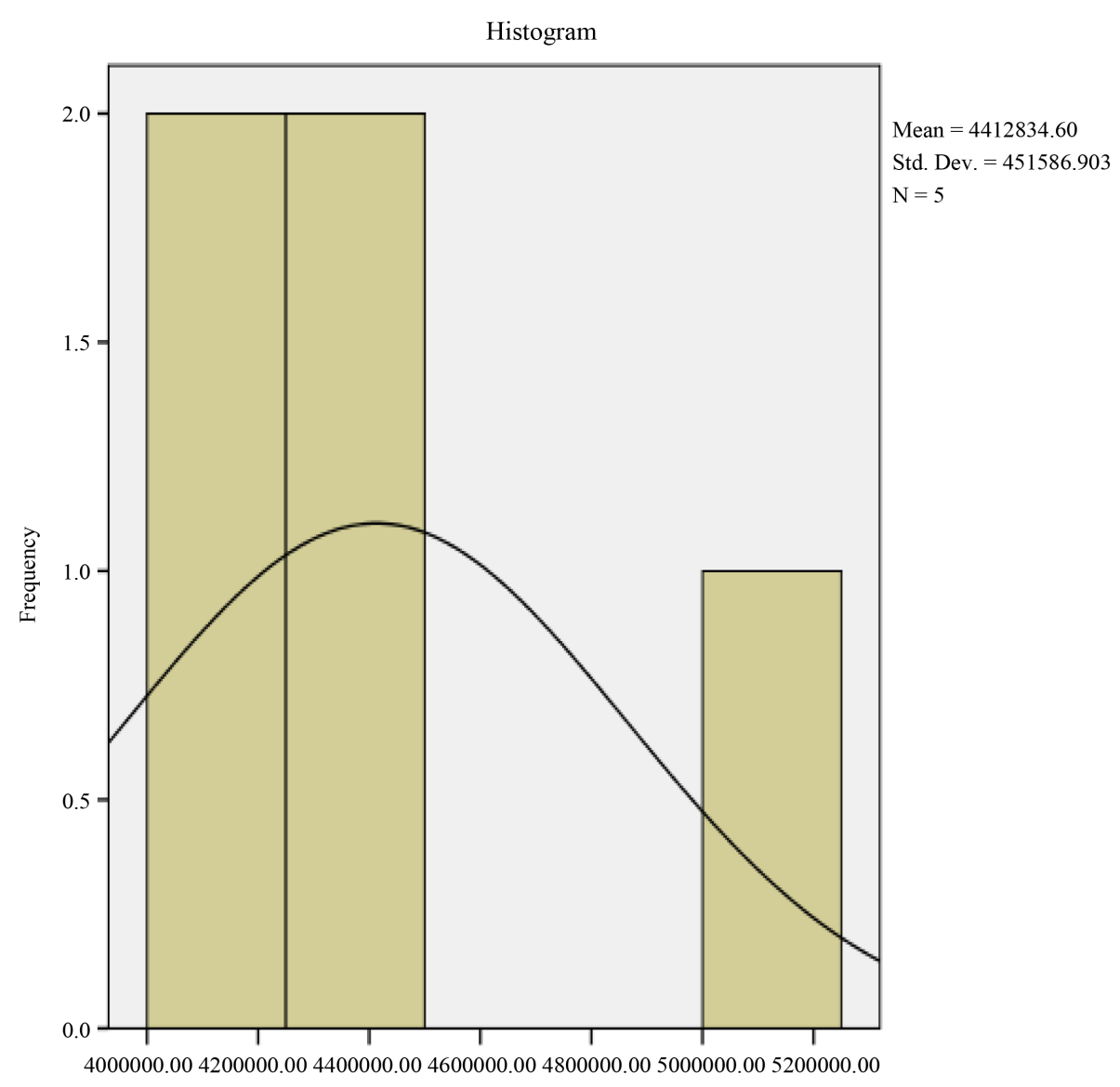

Houston Harris County Population 2010 to 2014

Figure 1. Houston Harris County population 2010 to 2014 histogram.

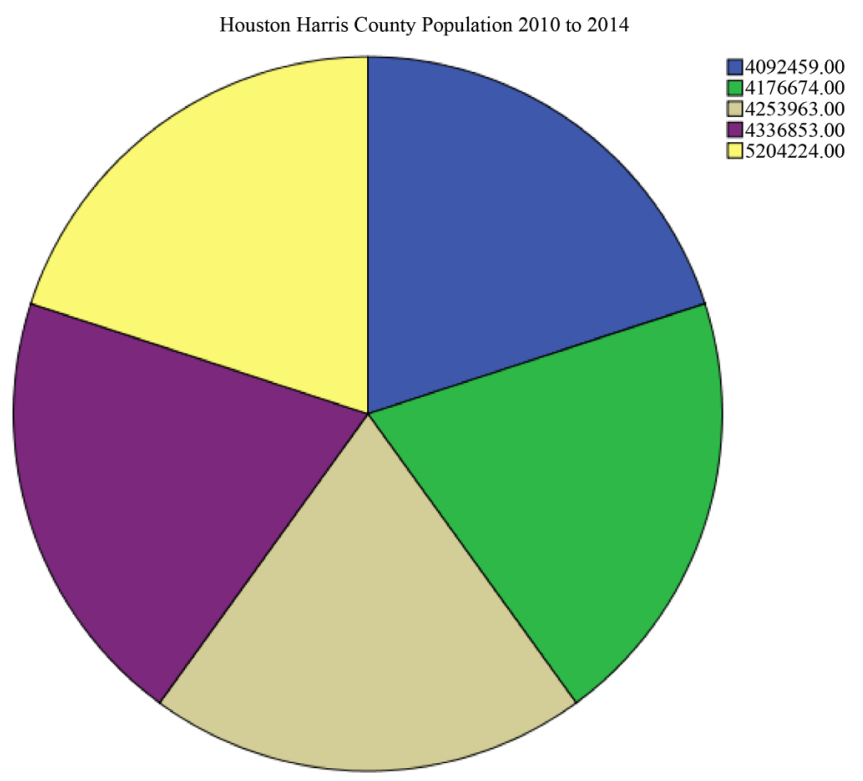

Figure 2. Houston Harris County population 2010 to 2014 Pie chart color coded and difference on the right-hand side. 


\subsection{Cause of Death}

As shown, Table 3, Table 4, Figure 3 and Figure 4 indicated the leading cause of death in Houston Harris County Texas between 2010 and 2014. In five years, the $(M)$ was 3293 while the $(M d)$ was 3377, the (Min) was 3060 and the (Max) was 3546 incidents' deaths in Houston Harris County Texas. It is advisable to pay attention to the quarterly percentile $25 \%, 50 \%$, and $75 \%$ differences in years as well as the data standard deviation and variance in Table 3. The (Std. E) was 97.7 but the (Std. D) was 218.4 which indicated a statistical significant differences increase from 3060 in 2010 to 3546 or 14\% in 2014 (see Table 3, Table 4, Figure 3 and Figure 4) as shown.

Table 3. Leading cause of death in Houston Harris County, Texas.

\begin{tabular}{|c|c|c|c|}
\hline \multicolumn{4}{|c|}{ Statistics } \\
\hline \multicolumn{4}{|c|}{ Leading Cause of Death in Houston Harris County, Texas } \\
\hline \multirow{17}{*}{$\mathrm{N}$} & & Valid & 5 \\
\hline & & Missing & 0 \\
\hline & Mean & & 3292.6000 \\
\hline & Std. Error of Mean & & 97.68040 \\
\hline & Median & & 3377.0000 \\
\hline & Mode & & 3060.00a \\
\hline & Std. Deviation & & 218.42001 \\
\hline & Variance & & $47,707.300$ \\
\hline & Skewness & & -0.218 \\
\hline & Std. Error of Skewness & & 0.913 \\
\hline & Kurtosis & & -2.562 \\
\hline & Std. Error of Kurtosis & & 2.000 \\
\hline & Range & & 486.00 \\
\hline & Minimum & & 3060.00 \\
\hline & Maximum & & 3546.00 \\
\hline & Sum & & $16,463.00$ \\
\hline & & 25 & 3063.5000 \\
\hline \multirow[t]{2}{*}{ Percentiles } & & 50 & 3377.0000 \\
\hline & & 75 & 3479.5000 \\
\hline
\end{tabular}

${ }^{\mathrm{a}}$ Multiple modes exist. The smallest value is shown.

Table 4. Leading cause of death in Houston Harris County, Texas.

\begin{tabular}{|c|c|c|c|c|c|}
\hline \multicolumn{6}{|c|}{ Leading Cause of Death in Houston Harris County, Texas } \\
\hline & & Frequency & Percent & Valid Percent & Cumulative Percent \\
\hline \multirow{6}{*}{ Valid } & 2010 & 1 & 20.0 & 20.0 & 20.0 \\
\hline & 2011 & 1 & 20.0 & 20.0 & 40.0 \\
\hline & 2012 & 1 & 20.0 & 20.0 & 60.0 \\
\hline & 2013 & 1 & 20.0 & 20.0 & 80.0 \\
\hline & 2014 & 1 & 20.0 & 20.0 & 100.0 \\
\hline & Total & 5 & 100.0 & 100.0 & \\
\hline
\end{tabular}




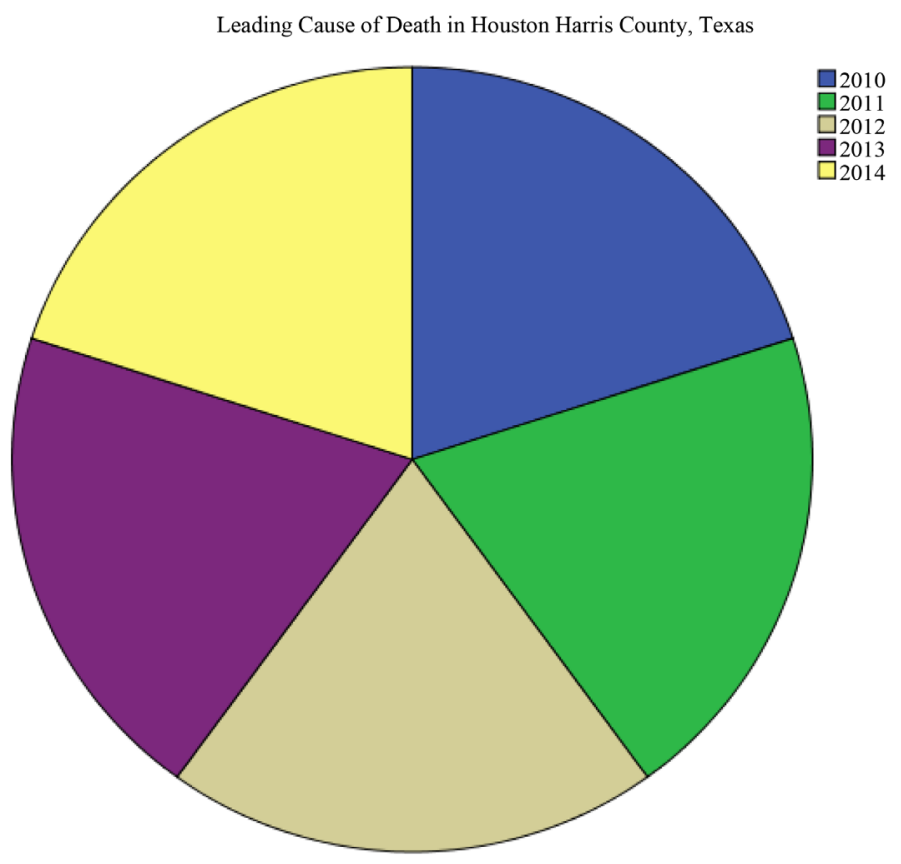

Figure 3. Leading cause of death in Houston Harris County, Texascolor coded and difference on the right-hand side.

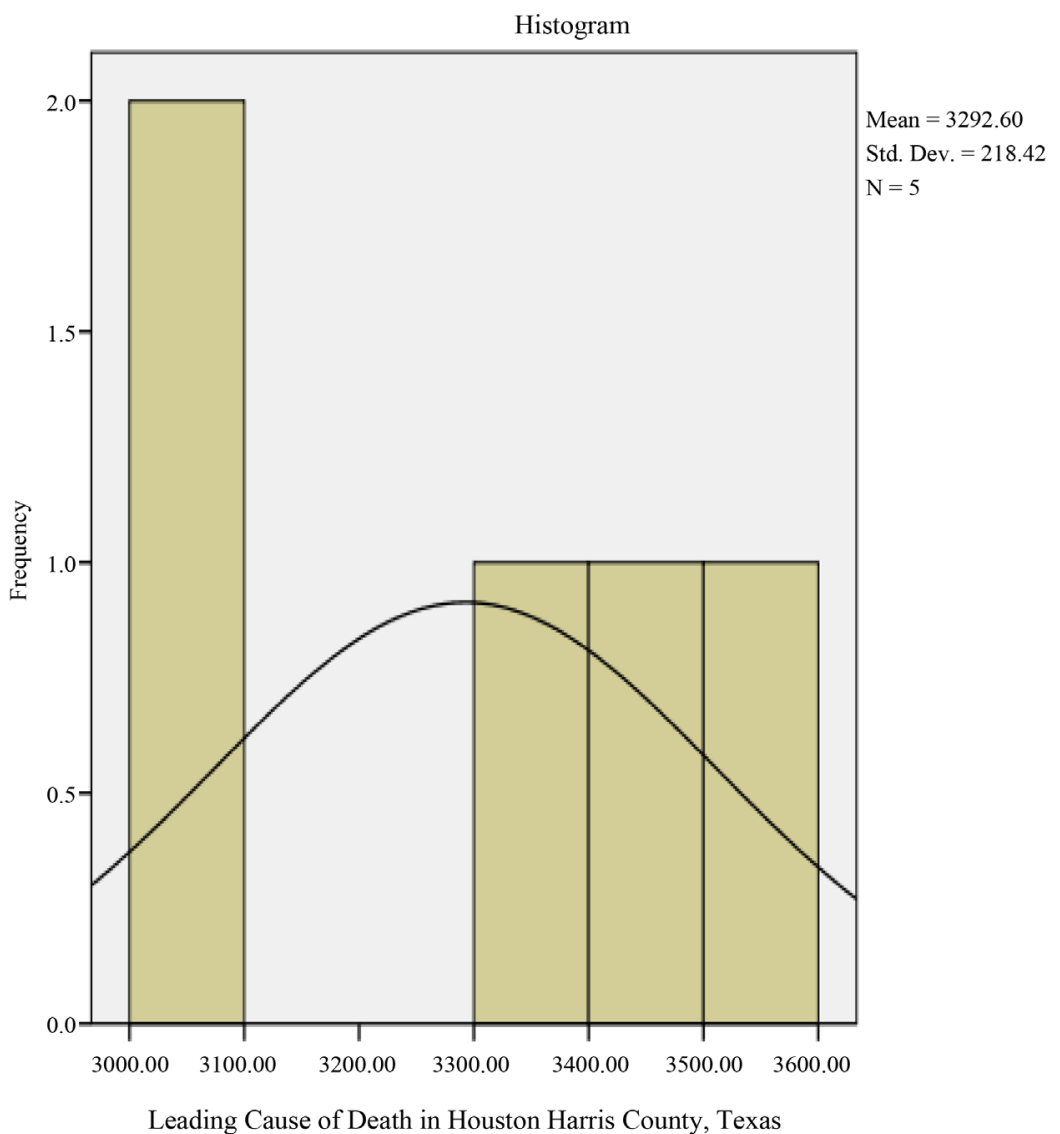

Figure 4. Leading cause of death in Houston Harris County, Texas. 


\subsection{Oil Barrel Price}

As shown, Table 5, Figure 5 and Figure 6 indicated the Oil Barrel Price Cumulative Percentage prices in Houston Harris County Texas between 2010 and 2014. In five years, the $(M)$ was $\$ 101$ per barrel, while the (Md) was $\$ 105$, the (Min) was $\$ 79$ and the (Max) was $\$ 117$ indicated a symmetrical drop in oil barrel prices in Houston Harris County, Texas and the surrounding areas. Furthermore, the (Std. E) was 97.7, but the (Std. D) was $\$ 15.50$ which indicated a statistical significant differences decrease from $\$ 117$ per barrel to $\$ 79$ per barrel or 33\% price drop from 2010 to 2014. The data indicated a symmetric drop instead of a systematic drop in oil barrel prices (see Table 5, Figure 5 and Figure 6) as shown. At the initial conclusion of this study, we found that Oil Barrel price has dropped from $\$ 117$ to $\$ 58$ or approximately 50\% drop in price. Once again, this is yet another symmetrical drop instead of being a systematical drop as required in commodity trades.

Table 5. Oil barrel price cumulative percentage.

\begin{tabular}{|c|c|c|c|c|c|}
\hline \multicolumn{6}{|c|}{ Oil Barrel Price 2010 to 2014} \\
\hline & & Frequency & Percent & Valid Percent & Cumulative Percent \\
\hline \multirow{6}{*}{ Valid } & 79.00 & 1 & 20.0 & 20.0 & 20.0 \\
\hline & 92.00 & 1 & 20.0 & 20.0 & 40.0 \\
\hline & 105.00 & 1 & 20.0 & 20.0 & 60.0 \\
\hline & 112.00 & 1 & 20.0 & 20.0 & 80.0 \\
\hline & 117.00 & 1 & 20.0 & 20.0 & 100.0 \\
\hline & Total & 5 & 100.0 & 100.0 & \\
\hline
\end{tabular}

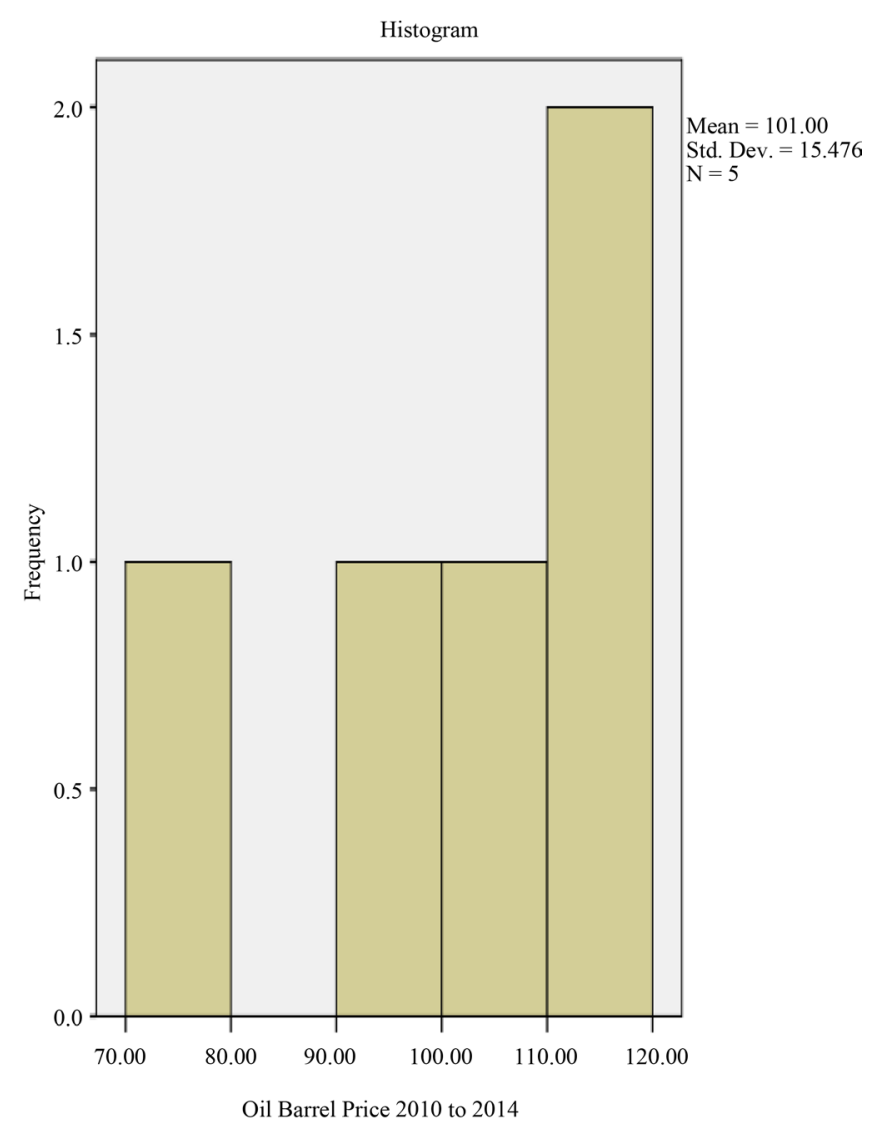

Figure 5. Oil barrel price cumulative percentage. 


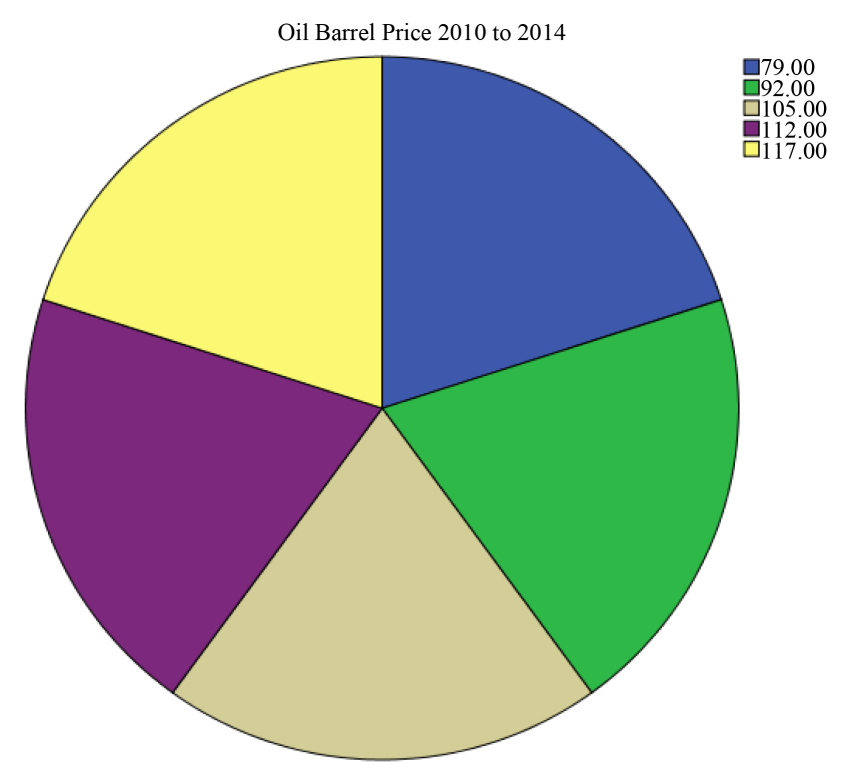

Figure 6. Oil barrel price cumulative percentage color coded and difference on the right-hand side.

\subsection{Gas Prices per Gallon}

The above statistics indicated the multiple modes of the gas prices per gallon from 2010 to 2014 in Houston Harris County, Texas and surrounding areas. The (Max) price was approximately 3.90 per a gallon while the (min) was approximately 2.70 and still dropping from 2010 to 2014. Also, the $(M)$ was 3.35, the (Med) 3.61, and the (Std.D) was 0.612 was shown in Table 6. Table 7 indicated $100 \%$ of valid and cumulative percentages of independent variables. Figure 8 and Figure 9 illustrated the statistical significant changes of prices of gas per gallon from 2010 to 2014 (see Figure 7 and Figure 8 as well as Table 6 and Table 7) as shown. At the conclusion of this data analysis, we found that gas per a gallon prices in Houston Harris County, Texas and surrounding areas dropped from approximately $3.90 \%$ to $2.15 \%$ or $45 \%$ drop per gallon. This is yet a symmetrical drop instead of a systematic drop that has not been seen in the oil industries since possibly in the early 1980s oil blots.

\subsection{Median Home Price}

The above statistical analyses indicated the median home price in Houston Harris County, Texas and surrounding areas between 2010 and 2014. The lower median home price in 2010 was approximately \$175,000; but, the medium home price in Houston Harris County, Texas jumped to approximately \$270,000 or 35\% increase in price in 2014. The mean $(M)$ of median home price in Houston Harris County Texas and surrounding areas was $\$ 205,200$ and the median (Med) price was $\$ 192,000$ between 2010 and 2014. The mode (Mod) was $\$ 175,000$, the (Min) was $\$ 175,000$ as well; but, the (Max) increased from $\$ 175,000$ to $\$ 269,000$ or 35\% between 2010 and 2014 , yet, it is still rising. Note that the standard deviation (Sta.D) was approximately $\$ 37,000$ or $17 \%$ median home price increase in less than a year. These analyses indicated that between 2010 and 2014, the median home price in Houston Harris County, Texas increased from $\$ 175,000$ to approximately $\$ 270,000$ or $35 \%$ as shown in (Table 8 and Table 9, as well as Figure 9 and Figure 10). This dramatic jump in median home price in less than possibly a year especially between (2013 \& 2014) indicated overwhelming statistical significant differences in median home prices in Houston Harris County, Texas and surrounding areas.

\section{Statistical Analysis of the Study's Findings}

There were several findings associated with this study. First, we found that the population of Houston Harris County Texas and surrounding areas increased from approximately 4,092,460 to 5,204,224 or 21\% between 2010 and 2014. This increase in population in Houston Harris, Texas and surrounding areas showed a symmetric 
Table 6. Gas price per gallon.

\begin{tabular}{|c|c|c|}
\hline \multicolumn{3}{|c|}{ Statistics } \\
\hline \multicolumn{3}{|c|}{ Gas Prices per Gallon in Houston Harris County, Texas } \\
\hline & Valid & 5 \\
\hline & Missing & 0 \\
\hline & Mean & 3.3320 \\
\hline & Std. Error of Mean & 0.30230 \\
\hline & Median & 3.6900 \\
\hline & Mode & $2.51 \mathrm{a}$ \\
\hline & Std. Deviation & 0.67596 \\
\hline & Variance & 0.457 \\
\hline & Skewness & -0.588 \\
\hline & Std. Error of Skewness & 0.913 \\
\hline & Kurtosis & -3.031 \\
\hline & Std. Error of Kurtosis & 2.000 \\
\hline & Range & 1.38 \\
\hline & Minimum & 2.51 \\
\hline & Maximum & 3.89 \\
\hline & Sum & 16.66 \\
\hline
\end{tabular}

${ }^{\mathrm{a}}$ Multiple modes exist. The smallest value is shown.

Table 7. Gas price per gallon.

\begin{tabular}{|c|c|c|c|c|c|}
\hline \multicolumn{6}{|c|}{ Gas Prices per Gallon in Houston Harris County, Texas } \\
\hline & & Frequency & Percent & Valid Percent & Cumulative Percent \\
\hline \multirow{6}{*}{ Valid } & 2014 & 1 & 20.0 & 20.0 & 20.0 \\
\hline & 2010 & 1 & 20.0 & 20.0 & 40.0 \\
\hline & 3.69 & 1 & 20.0 & 20.0 & 60.0 \\
\hline & 2011 & 1 & 20.0 & 20.0 & 80.0 \\
\hline & 2012 & 1 & 20.0 & 20.0 & 100.0 \\
\hline & Total & 5 & 100.0 & 100.0 & \\
\hline
\end{tabular}

or sudden population increase, instead of a systematic or gradualpopulation growth which could have been easier to effectively, efficiently, and proficiently manage from all statistical standpoints as compared to sudden increase in population. Also, Houston Harris County, Texas and surrounding areas experienced approximately 219,000 population standard deviation from the expected statistical normalcy. Additionally, we found that $21 \%$ population increase in less than 5 years or 219,000 population standard deviation from the population growth norms indicated a significant statistical differences' increase in Houston Harris County, Texas and surrounding areas population growth.

Secondly, we found that between 2010 and 2014, Houston Harris County, Texas and surrounding areas leading cause of death was roads' accidents. Houston and surrounding areas experienced approximately 486 increases in road accidents deaths between 2010 and 2014. For example, in 2010, the roads accidents fatalities were 3060 victims annually as compared to 3546 or $14 \%$ increase in death rate in 2014 . We further found that the roads accidents deaths showed a standard deviation of 218 differentiations in deaths between 2010 and 2014 which indicated yet another negative statistical significant difference in roads accidents deaths in Houston and 
Table 8. Medium home price in Houston.

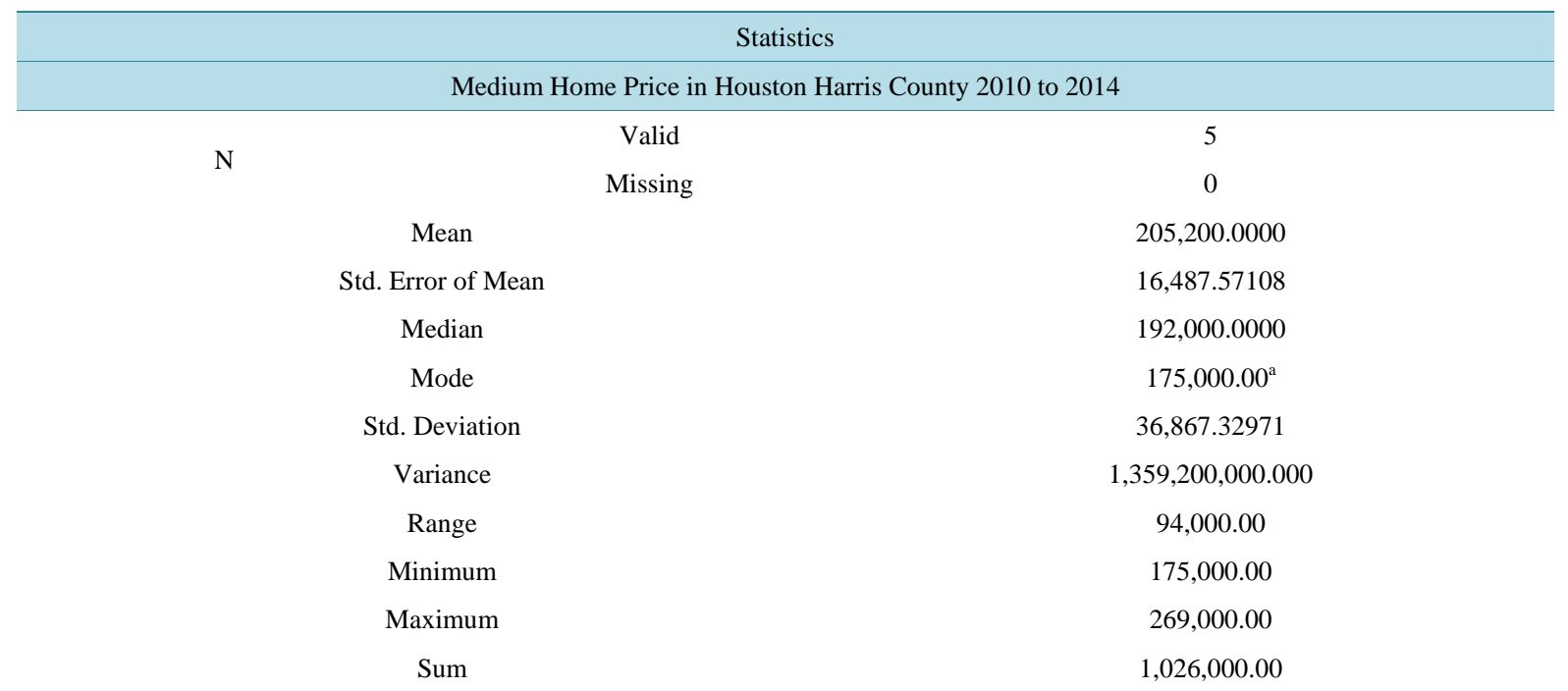

${ }^{a}$ Multiple modes exist. The smallest value is shown.

Table 9. Medium price from 2010 to 2014.

\begin{tabular}{|cccccc|}
\hline & \multicolumn{5}{c}{ Medium Home Price in Houston Harris County 2010 to 2014} \\
\hline \multirow{4}{*}{ Valid } & Frequency & Percent & Valid Percent & Cumulative Percent \\
\hline & $175,000.00$ & 1 & 20.0 & 20.0 & 20.0 \\
& $189,000.00$ & 1 & 20.0 & 20.0 & 40.0 \\
& $192,000.00$ & 1 & 20.0 & 20.0 & 60.0 \\
& $201,000.00$ & 1 & 20.0 & 20.0 & 80.0 \\
\hline
\end{tabular}

Gas Prices per Gallon in Houston Harris County, Texas

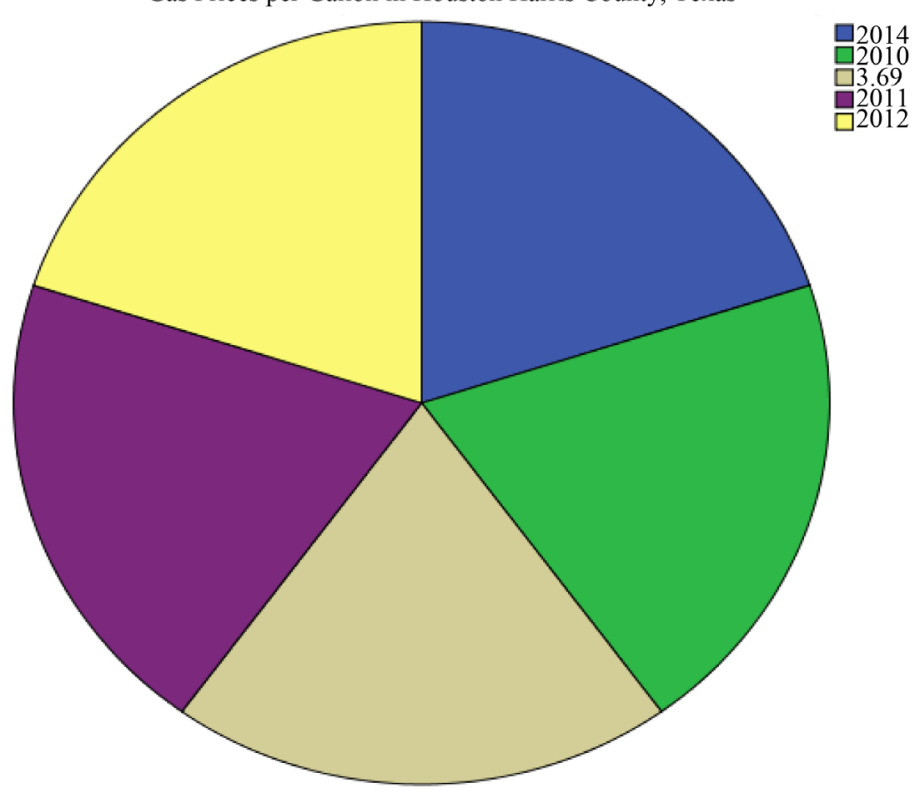

Figure 7. Gas price per gallon color coded and difference on the right-hand side. 


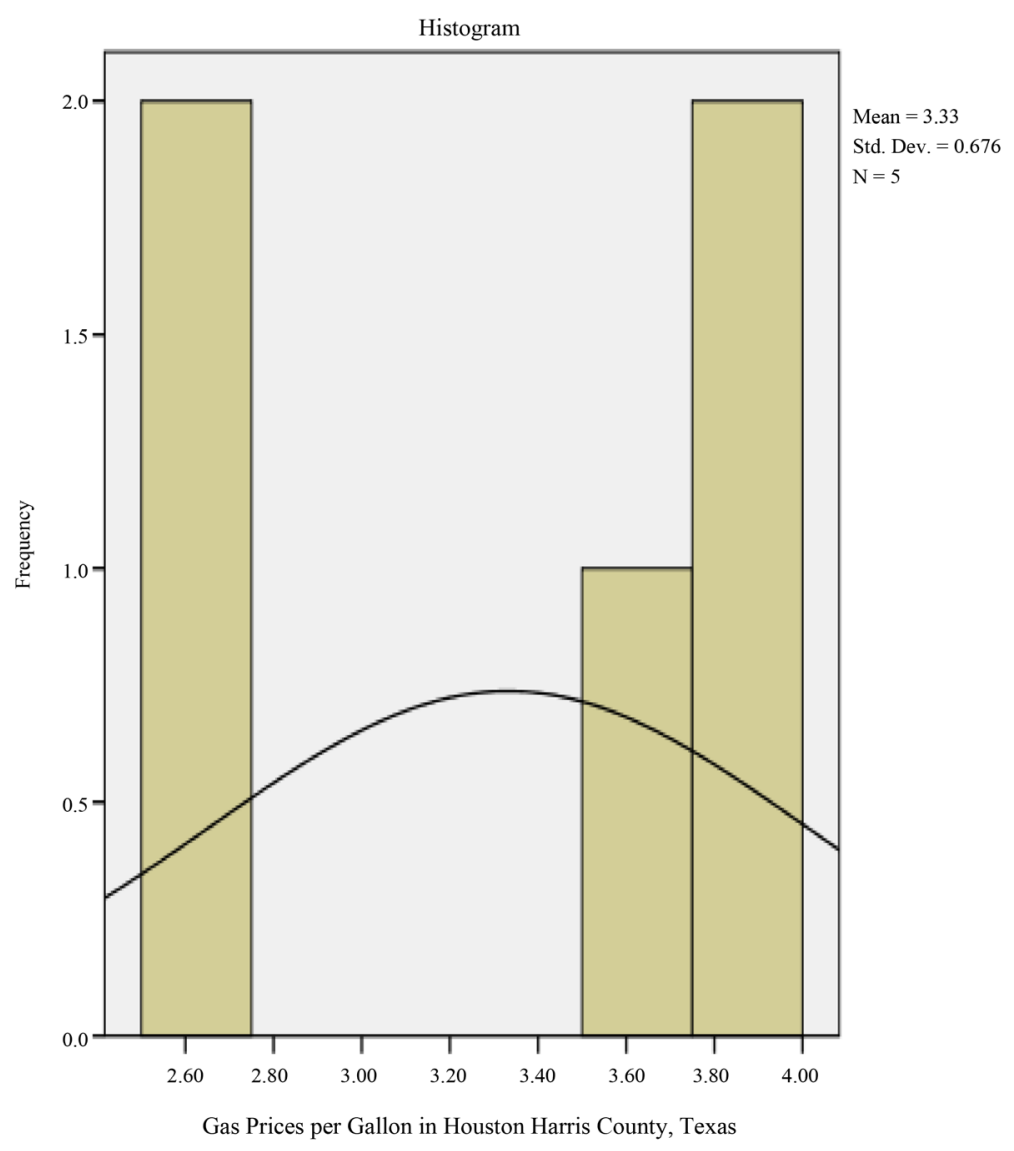

Figure 8. Gas price per gallon.

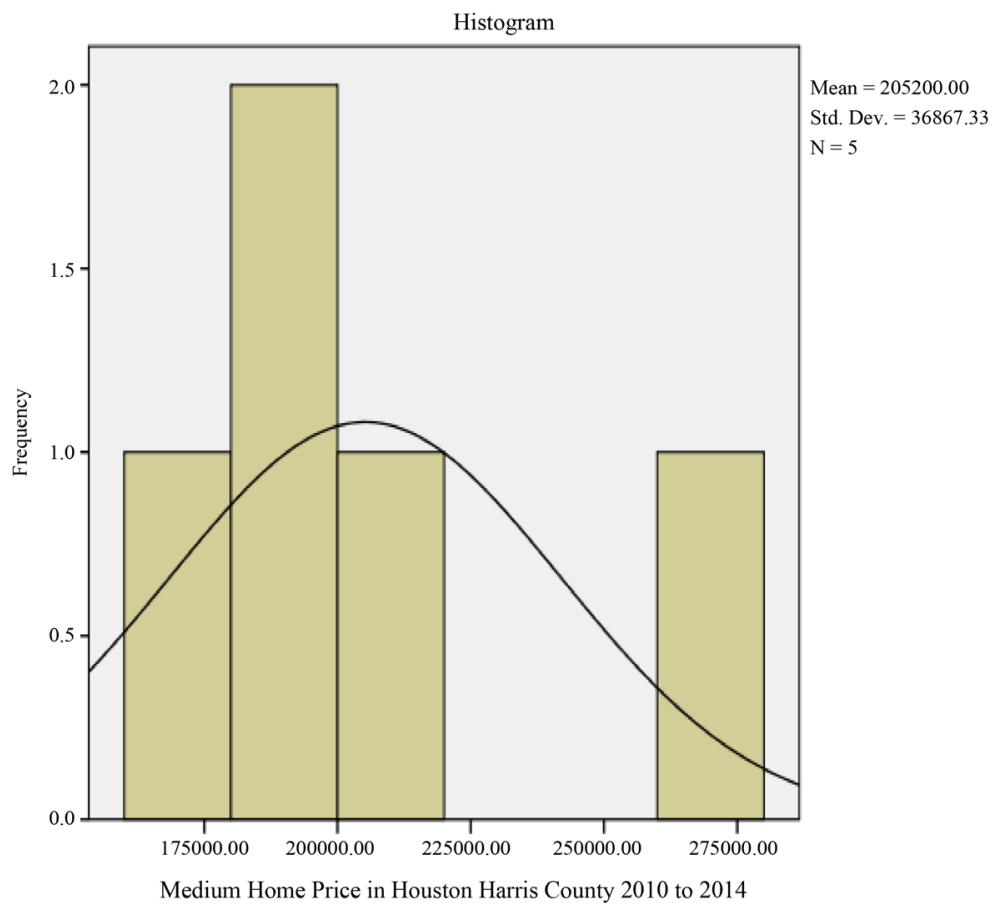

Figure 9. Frequency median price histogram distribution. 


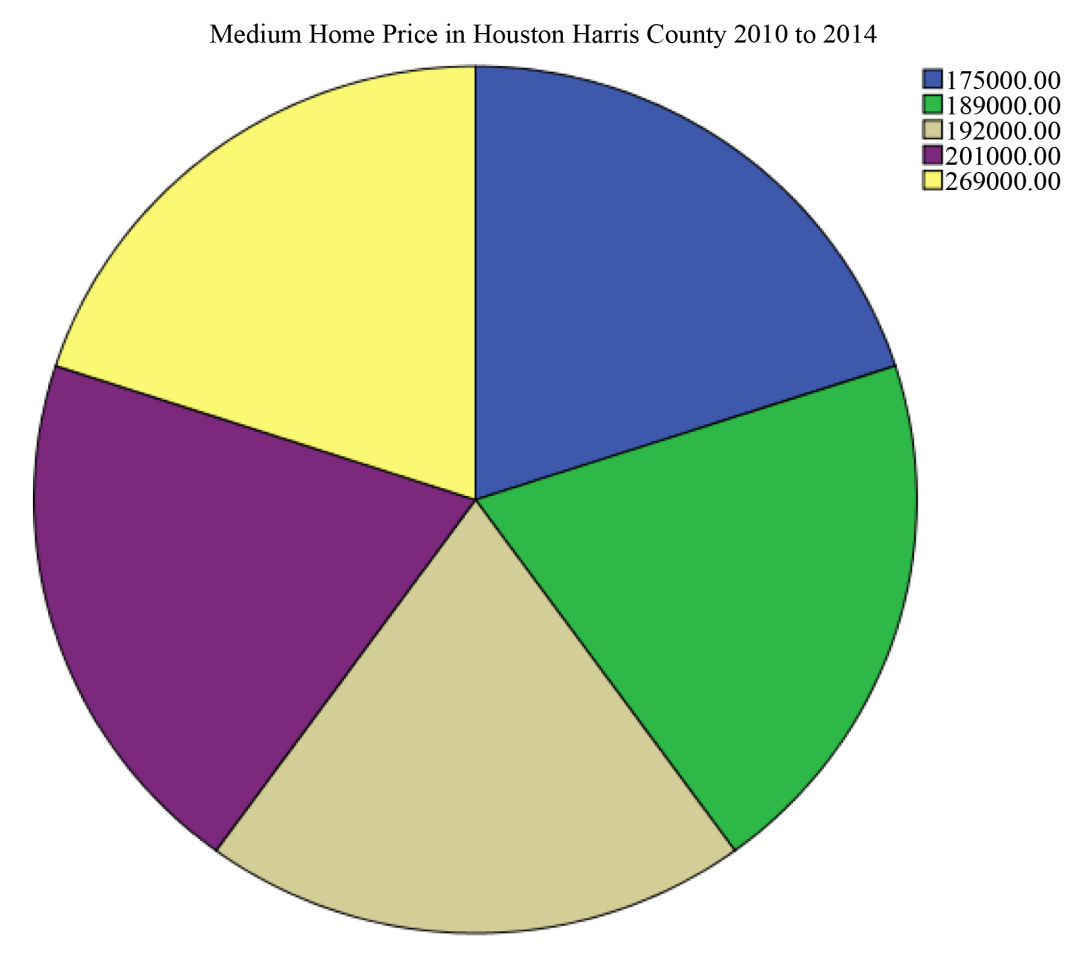

Figure 10. Medium home price in Houston Harris County 2010 to 2014 Pie chart color coded and difference on the right-hand side.

surrounding areas.

Additionally, the price of Oil Barrel price is yet another disturbing area that we noted in this study. We found that between 2010 and 2014 based on statistical calculations, oil barrel price dropped from $\$ 117.00$ per barrel to $\$ 79.00$ and still falling daily. At the conclusion of these statistical calculations, the oil barrel price has dropped from $\$ 117.00$ to a record price of $\$ 50.00$ in 2014. This drop is not only a record drop since 2007, but showed a symmetric decrease of approximately $54 \%$ which is upheld when dealing with oil price in America and internationally. The drop in oil barrel prices also affected its primary product derivative which is gas. Gas is one of the most popular derivatives of oil as a product output and oil as a primary input of energy productivities.

The price of oil barrel drop in 2014 had a one to one correspondence relationship with the price of a gallon of gas in Houston Harris County, Texas and surrounding areas. Based on our statistical analyses, we found that between 2010 and 2014, a gallon of gas dropped from approximately \$3.90 per gallon to \$2.51 in 2014 and still dropping on a daily basis. At the initial statistical calculations of study, we noticed that the gallon of gas had dropped as low as $\$ 2.00$ or approximately 51\% in late 2014 and still falling in the first week of 2015 as low as $\$ 1.95$ per a gallon. From a statistical standpoint, this is a severe symmetric financial reduction for the energy industries in Houston and surrounding areas.

The most interesting finding of this study is the median home prices in Houston Harris County and surrounding areas. We found that the median home price in Houston and surrounding areas was $\$ 175,000$ in 2010 while the mean price was $\$ 192,000$ between 2010 and 2014. The minimum median price was also $\$ 175,000$ in 2010, but the maximum price rose to $\$ 270,000$ or approximately $35 \%$ in 2014 . Additionally, we noted that the median home prices are still on the rise daily reaching almost based on commercials and advertisements. The median home price in Houston and surrounding areas in 2014and beyond appeared to be the only bright note for the real estates' employees, as well as the sellers in this study. However, as for buyers in 2014, the median home price showed a mean standard deviation of $\$ 36,867$ or $17 \%$ increase in median price. This $\$ 36,867$ or $17 \%$ increase from 2013 to 2014 highly exceeded any median property earned value in 5 to 7 years than in one year. In light of these disturbing study's findings, we observed some disturbing finding that were not the primary purpose of this study. 


\section{Discussions and Conclusions}

During the period of conducting this study, we found that the price of a barrel of oil and its derivatives such as gas and other oil products took a symmetric fall. We further observed that the local oil producing companies as well as international companies such, as Organization of the Petroleum Exporting Countries (OPEC), failed and practically refused to import simple economics formula. For example, OPEC countries argued that regardless of more than 55\% drop in oil barrel price and 52\% of its derivatives, OPEC would continue to over-produce oil. Also, the national companies associated with hydraulic fracking systematically refused to scale back in production in light of the products prices' drops. This formula goes against the "Law of Demand and Supply (LDS)," the "Break Even Analysis (BEA)," "Cost Benefit Analysis CBA," and, above all, "Equilibrium Price Theory (EPT)"

The simple "law of demand and supply" states that the higher the demand is, the higher the supply is and vice versa. Based on this simplified definition of the collaborations between demand and supply, both the OPEC and American oil drillers have totally undermined simple, economic law or theory of demand and supply. Also, the break even analysis theory emphasized that in any investments; at one point of the investments' processes one should break even in order to float financially, instead of sink. Further, for anybody to successful and financially stay afloat indefinitely, one should be aware of the fundamental principles of CBA, BEA, and EPT to mention a few. However, failure to comply with the above enlisted economical theories and laws leads to what we are currently observing today in OPEC, Europe, Russia, other oil producing countries and international currencies against the American Almighty Dollars. It is arguable but, many believed and gave state repeatedly that those OPEC countries such as Russia, Saudi Arabians, and Africa oil-producing OPEC countries cannot afford to reduce volumes of production because it will decimate their countries' annual or fiscal budgeting and finance. Today, it is unprecedented and disturbing; but, failure to wisely implement simple economical laws or theories as analyzed above, will surely indicate the beginning of the oil burst, like what we all have experience in the early 1980s internationally, but, only time will tell.

\section{Implication of the Study}

Locally, another pressing issue associated with the impacts of hydraulic fracking in Houston Harris County, Texas and surrounding areas is railroads' traffics. It has been observed that railroads' activities in the areas have tremendously increased to possibly a record level. For example, the railroads' tracks are running in thousands miles across Houston Harris County, Texas and surrounding areas. Besides the above, it appears that majority of the cargos are oil harvest from hydraulic fracking activities based on the crude oil black tanks. Furthermore, the tanks that carried this oil from coast to coast have tanks' capacities that ranged between 250,000 to 380,000 gallons of oil each. Surprisingly, agriculture companies have repeatedly complained that the railroad companies have placed their well public needed agricultural products such as corn, vegetables, and fruits in the back burners. They argued that the transportation of oil is more profitable to the rail companies than supplying food products to Americans. These complaints are yet to be verified; and, the public safety concern issues associated with the railroads' oil tanks is yet another unresolved public safety issue that needs to be professionally investigated.

In summation, there is no doubt that the implications created by the oil field drilling companies in Houston Harris County, Texas and surrounding areas cannot and must not be undermined. On one hand, the oil field drilling companies appeared to be singularly responsible for the symmetric and systematic population increase in the areas from 4.2 to almost 5.4 million in less than four years. Also, the population growth led to fatal roads' accidents increase from low 3000 annually to almost 3500 in less than four years. Also, the oil field drilling companies created and imported employees who are not native Houstonians; but, they came from outside Houston Texas and surrounding areas. Above all, these oil drilling companies employees contributed to symmetric as well as a systematic median home price increase in Houston Harris County and surrounding areas by simply pricing native Houstonians from effectively participating in the process.

The oil barrel price is yet another area where hydraulic fracking impacted Houston Harris County Texas and surrounding areas and beyond. Based on the increase of oil production in Texas in particular and nationally, in general, the OPEC could no longer sustain stable prices for their international oil productivities. Majority of OPEC members blamed hydraulic fracking as a new international phenomenon that is decimating oil producing countries from Middle East to Russia and not to mention Africa and European countries. According to financial analysts, hydraulic fracking has saturated the oil market, and the OPEC countries could no longer effectively, efficiently, or proficiently compete internationally. However, American hydraulic fracking states continue to 
drill oil as much as possible, which undermines the oil barrel price daily. For example, at the end of this study, oil barrel price stood at $\$ 50$ a barrel and the gallon of gas drops below $\$ 2.00$ for the first time in almost 7 years. These drops have some economic impacts internally and externally.

The OPEC countries are currently having problems in balancing their fiscal or annual budgets especially those countries leaders who singularly depend on oil to implement their budgets. However, as the oil saturation takes its victims, OPEC insisted on produce more oil regardless until Americans give up with the hydraulic fracking new phenomenon. Conversely, American hydraulic fracking companies continue to produce oil regardless of the significant repeated drop in price. These approaches work against another economic formula when dealing with a complimentary products or services. In any complimentary analysis, it is believed that complimentary products/services are always at its best if both produce complement one another. Historically, the rise of oil barrel price, the price of gas gallon price, and the increase in net oil companies' revenues and vice versa has always been expected with time. This analysis falls into the critical area that for a complimentary good/services to be effective, efficient, and proficient, both must move in a positive one to one correspondence and not negatively or in opposite directions. In this case, hydraulic fracking companies and OPEC are currently moving into unknown areas that only time could determine the future of oil as an energy product. As such, American hydraulic fracking companies and OPEC should find a common ground in order to address collectively some of the implications created by oil over productivities locally, nationally, and internationally.

In the final analysis, from a public policy standpoint, there is no doubt that the implications and complications associated with hydraulic fracking in Houston Harris County, Texas and surrounding areas cannot be undermined. Basically, hydraulic fracking activities in Houston had created compartments that make living simple lifestyle almost impossible to achieve. The current public policy implications are deplorable conditions of Houston roads, endless driving traffics, and repeated roads accidents not to mention the increase in accidents' fatality. Furthermore, hydraulic fracking has made living in affordable housing in Houston Harris County, Texas and surrounding areas near impossible. This is the case because with a marginal home price increase of almost $38 \%$, many native Houstonians cannot afford buying such houses while their paycheck remain unchanged in more than 10 years. Above all, the possible positive shining light associated with this quagmire is low gas price in Houston Harris County, Texas and surrounding areas. In light of the possible singular positive outcome, it is fair to note that the hydraulic fracking activities has created complicated public policy, public safety, and public health implications that need to be revisited by all public leaderships in order to be effective, efficient, and proficient in the near future to come. Until these complications and implications created by hydraulic fracking in Houston, Texas, nationally, and possibly internationally are addressed and resolved holistically and comprehensively, hydraulic fracking will continue to be apsychological irreconcilable differences crisis that the world needs to resolve.

\section{Recommendations}

The recommendation of this study covers four major entities when dealing with the implications of hydraulic fracking in Houston Harris County, Texas and surrounding areas. These entities are the Oilfields drilling companies, the environmentalists, and the city of Houston and surrounding areas leaderships, and state of Texas leadership to be specific.

\subsection{Recommendations for the Oilfields Drilling Companies}

1) The Oilfields drilling companies need to conduct comprehensive environmental research study on the impacts of oil and gas drilling on Houston and surrounding areas.

2) The Oilfields drilling companies should be willing to address some noted issues associated with companies' roads activities in Houston and surrounding areas with the local and state leaderships.

3) The Oilfields drilling companies should find a way to stabilize the barrel price of oil as well as the gallon price as to avoid a burst.

4) The Oilfields drilling companies should be held accountable, responsible and transparency about the road ready conditions of their commercial vehicles as well as their commercial drivers.

5) The Oilfields drilling must be willing to be transparent with any noticeable concerns with the neighborhoods drilling activities and be proactive instead of reactive.

6) The Oilfields drilling companies should be willing to put their monies where their mouths are, instead of 
simply counting their daily, weekly, monthly, and yearly profits at the expense of native Houstonians.

7) Finally, since hydraulic fracking has become a fundamental oil and gas production international prices' formula, Oilfields Drilling companies should and must collaborate with OPEC as to stabilize the barrel price of oil internationally.

\subsection{Recommendations for the US State of Texas and Local Environmentalists}

1) The environmentalists should find common grounds with the oil-field companies as well with other entities as to positively collaborate in conducting drilling activities on environmental impacts research studies.

2) The environmentalists should conduct and share studies' findings with all the oil-field drilling companies, the cities, the state, and the federal leaderships as to find grounded collective approaches in addressing drilling related challenges across the board.

3) The environmentalists should be willing to be proactive instead of reactive if addressing oil drilling impacts in Houston Harris County, Texas and surrounding areas.

\subsection{Recommendations for the City of Houston Harris County Leaderships}

1) Both the city and the county leadership should collaborate in resolving the overnight implications created by the oilfields drilling companies in Houston Harris, Texas and surrounding areas.

2) Secondly, they should allow road law enforcement officers to be more proactive rather than reactive to keep our roads safer for all native and new Houstonians.

3) The leaderships should effectively, efficiently, and proficiently use their portion/s of proposition 1 funds in addressing the impacts created by oil field drilling companies in the areas.

\subsection{Recommendations for the State of Texas Leaderships}

1) Texas leaderships should understand that the oil drilling companies' leaderships has systematically forced themselves into certain drilling areas such as Denton, Texas to mention a few which needs to be addressed.

2) Texas leadership should compel oil drilling companies to be transparent to all in their drilling areas and beyond.

3) Texas leadership should compel the oil drilling companies to ensure that all their commercial and private vehicles are roads ready.

4) Texas leadership should compel Texas Department of Public Safety (DPS) to stiffen up qualifications requirements in obtaining private and commercial driver licenses in the state of Texas.

5) Finally, Texas leadership should and must pay attention to the public approval of proposition 1 in the recent midterm election by utilizing the approved funds efficiently, effectively and proficiently in addressing the quagmires created by the oil field drilling companies in the state of Texas.

\subsection{Recommendations for the US EPA}

1) EPA should continue to address the needs of native Houston's citizens by comprehensively investigating their environmental complaints.

2) EPA should conduct independent research studies to investigate these complaints and be ready to share its findings positively with all involved entities.

3) EPA should implement sanctions if needed if the oil and gas drilling companies fail to correct unequivocal noted environmental activities errors expeditiously.

EPA should promote transparency on all oil and gas drilling companies which will eventually unequivocally lead to improved management oversights, accountability, and responsibility that could enhance environmental impacts of oil and gas drilling in Houston Harris County, Texas and surrounding areas.

\section{Acknowledgements}

We want to use this opportunity to thank "University of Phoenix Houston Campus Colloquium Research Drive" which has motivated this study. We also want to thank the UOP's Campus College Chair, Colloquium academics leaders, administrators, committee, and team members for encouraging collaborative holistic partici- 
pations in research studies; which should be fundamentally intriguing and eventually helpful to society as a whole.

\section{References}

[1] Olsen, L. (2014) Oilpatch Traffic—and Rogue Trucks—Boost Death Toll. Lise Olsen, Investigative Reporter, Houston Chronicle, 13 September 2014.

[2] Schneider, A. (2014) Deadly Accidents Involving Trucks Tied to Fracking Operations Surge. Andrew Schneider, 15 September 2014.

[3] Elger, E. (2008) Transparency in a New Global Order: Unveiling Organizational Visions.

[4] Elger, E. (2011) Secrecy and Transparency: The Politics of Opacity and Openness. Theory, Culture and Society, 28, 7-25.

[5] Schauer, F. (2011) Transparency in Three Dimensions. University of Illinois Law Review, 2011, 1339-1358. http://illinoislawreview.org/wp-content/ilr-content/articles/2011/4/Schauer.pdf

[6] Theoharis, A.G. (1998) A Culture of Secrecy: The Government versus the People’s Right to Know.

[7] Michael, J. (1990) The Politics of Secrecy: Confidential Government and the Public's Right to Know. London.

[8] Creswell, J.W. (2009) Research Design: Qualitative, Quantitative, and Mixed Methods Approach. 3rd Edition, Sage Publications, Inc., Thousand Oaks.

[9] Frankfort-Nachmias, C. and Nachmias, D. (2000; 2008) Research Methods in the Social Sciences. 6th Edition, Wadsworth, New York.

[10] Acock, A.C. (2005) Working with Missing Values. Journal of Marriage and Family, 67, 1012-1028. http://dx.doi.org/10.1111/j.1741-3737.2005.00191.x

[11] Ader, H.J. (2008) Chapter 13: Missing Data. In: Ader, H.J. and Mellenbergh, G.J., Eds., with Contributions by Hand, D.J., Advising on Research Methods: A Consultant’s Companion, Johannes van Kessel Publishing, Huizen, 305-332.

[12] Ader, H.J. and Mellenbergh, G.J. (2008) Inference and Missing Data. Biometrika, 63, 581-592. http://dx.doi.org/10.1093/biomet/63.3.581

[13] Messner, S.F. (1992) Exploring the Consequences of Erratic Data Reporting for Cross-National Research on Homicide. Journal of Quantitative Criminology, 8, 155-173. http://ieeexplore.ieee.org/xpls/abs_all.jsp?tp=\&arnumber=4274271\&isnumber $=4274116$ http://dx.doi.org/10.1007/BF01066742

[14] Stoop, I., Billiet, J., Koch, A. and Fitzgerald, R. (2010) Improving Survey Response: Lessons Learned from the European Social Survey. Wiley, New York. http://dx.doi.org/10.1002/9780470688335

[15] Allison, P. D. (2001) Missing Data. 1st Edition, Sage Publications, Inc., Thousand Oaks.

[16] Stake, R. (2005) The Art of Case Study Research. Sage, Thousand Oaks.

[17] Rubin, D.B. (1976) In Ader, H.J., Mellenbergh, G.J. 2008) Inference and Missing Data. Biometrika, 63, 581-592. http://biomet.oxfordjournals.org/content/63/3/581.short http://dx.doi.org/10.1093/biomet/63.3.581

[18] Rubin, D.B. and Little, R.J.A. (2002) Statistical Analysis with Missing Data. 2nd Edition, Wiley, New York.

[19] Atatah, Rutledge, Thomas and Settles (2013) Statistical Significant Differences Multiplier (SSDM) in Analysis of Variance in Recidivism between Special Needs Offenders and Regular Offender Populations in Texas. ProQuest Published Dissertation, Walden University, Minneapolis. 